\title{
Analysis of the Demand for Berries in Mexico: An Application of the Almost Ideal Demand System (AIDS) Model
}

\author{
Valdes-Zamora, Alejandra ${ }^{1}$; García-Mata, Roberto ${ }^{1 *}$; Martínez-Damián, Miguel A. ${ }^{1}$; García-Sánchez, Roberto C. ${ }^{1}$ \\ ${ }^{1}$ Colegio de Postgraduados, Campus Montecillos. Carretera México-Texcoco km 36.5, Montecillo, \\ Texcoco, Estado de México, México. \\ ${ }^{*}$ Corresponding author: rory@colpos.mx
}

\begin{abstract}
Objective: To identify the factors affecting the demand for berries in Mexican households, as well as the behavior in face of variations in economic income.

Design/Methodology/Approach: In order to analyze the demand, microdata were used from the National IncomeExpenditure Survey of Households 2018 (Encuesta Nacional Ingreso Gasto de los Hogares, ENIGH) from the National Institute of Statistics and Geography (Instituto Nacional de Estadística, Geografía e Informática, INEGI), and for its modelling the Almost Ideal Demand System (AIDS) model was used.

Results: Because of their Marshallian elasticity, berries are an elastic good (-1.0316), and because of their expenditure elasticity they are a luxury good (1.0691). In terms of crossed Marshallian elasticities, sweet fruits and sugary beverages were identified as substitute goods with elasticity of 0.0013 and 0.0380 , respectively, while semi-acid fruits and melons would be complementary goods, with elasticities of -0.0191 and -0.0184 , respectively.

Study Limitations/Implications: Given that most of the time series of the berries lack disaggregation and sufficient information, it is difficult to analyze each component of the group separately; therefore, it was decided to analyze the group of berries and its relationship with other goods; in addition, the ENIGH database was selected, which provides more information.

Conclusions: There are state differences in the response to changes in prices and income with regard to the demand for berries, so that facing a generalized increase in household income consumption would increase much more in the center of the country than in the south-southeast.
\end{abstract}

Keywords: berries, elasticity, microdata, demand system

\section{INTRODUCTION \\ In Mexico,}

the national consumption per capita of berries (strawberry, raspberry, blackberry and cherry) increased at an average annual rate of $14.56 \%$ in the $2010-2017$ period. In 2017, their consumption was $6.95 \mathrm{~kg}$ average per inhabitant, which meant more than three times what was observed in 2010 (1.83 kg). The exports of berries have shown a similar dynamic, in average and throughout the same period; the exchange of berries with the rest of the world increased at an annual average rate of $28.17 \%$.

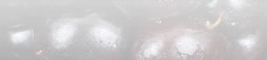

Agroproductividad: Vol. 14, Núm. 5, mayo. 2021. pp: 11-16. Recibido: julio, 2020. Aceptado: abril, 2021. Imagen de PublicDomainPictures en Pixabay 
The importance of berries in the national agrifood market is due to the window of opportunity that consumers of medium and high income represent, who are willing and able to pay a relatively high price compared to other fruit groups and who generally appreciate the products that promote health (FIRA, 2016). There are findings that relate the consumption of berries with positive effects in combatting different types of diseases, for example Miller et al. (2019) and Solverson et al. (2018)

Such dynamism in the demand, both domestic and foreign, has brought an important increase in the cultivation of these fruits in various regions of the country (Rivera \& Blanco, 2018). According to information from FIRA (2016), this has led to Mexico becoming positioned as the fifth world producer of berries (leaving out cherries). Therefore, the factors that affect the demand for berries in Mexican households were identified in this study, with the aim of quantifying its relationship with other products, as well as the behaviors of households in view of variations in their economic income. This was done by estimating the own, expenditure and crossed price elasticities.

\section{MATERIALS AND METHODS}

The Mexican demand for berries was modelled using microdata from the ENIGH by INEGI for the year 2018 (https://www.inegi.org. mx/programas/enigh/nc/2018/); specifically, the following sections were used: Expenditure in households (household expenses), Financial and capital income and receipts of members of the household (income), and Main variables per household (household concentrate). These bases (sections) were linked according to their household key. This aggregate base was used to generate six food groups, with emphasis in fruit products, which are components of the expenditure in Mexican households (Table 1).

The inspection of the ENIGH (2018), with the incorporation of the expansion factors (defined as the inverse of the probability of selection, and which is a measure of representativeness per observation), made evident that Mexican households, in general, are not habitual fruit consumers, since out of 74,582 representative households with valid information in the survey, only $1.35 \%$ indicated consuming berries (corresponding on average to consumers of high income, see Valdés-Zamora (2020)), 26.32\% acid fruits, $33.40 \%$ sweet fruits, $22.69 \%$ semi-acid, and $7.05 \%$ melons. On the other hand, in the case of sugary beverages, $68.87 \%$ of the households reported consuming the good.

Having said that, regarding the expense destined solely to the purchase of the six groups analyzed, on average the households destined $0.6942 \%$ to purchasing berries, $10.7321 \%$ to acid fruits, $13.15251 \%$ to sweet fruits, $12.5007 \%$ to purchasing semi-acid fruits, $2.8462 \%$ to melons, and $59.38 \%$ of the expenditure to the purchase of sugary beverages. This, in part, reaffirms what was exposed previously and it is because Mexican households are not habitual consumers of fruits.

Regarding the logarithm of the average prices that consumer households reported, we find that berries exhibited the highest average price with 4.01, followed by melons with 3.11, acid and semi-acid fruits with 2.5, and sugary beverages with 1.99, which places the latter as the cheapest compared to the fruit groups, which could explain in part their higher preference.

One of the problems when using microdata is that when the households report zero consumption of one of the goods, they generate the price of the product as an absent value; however, to give solution to this problem and not exclude these data, the imputation process known in the literature as k-nearest neighbor imputation (KNN) was used. Only one neighbor was

\section{Table 1. Food groups of fruits and sugary drinks and their components, 2018.}$$
\text { Groups Components }
$$

\begin{tabular}{l|l} 
(1) Berries & Cherry, raspberry, strawberry, blackberry
\end{tabular}

Guava, lime, lemon, tangerine, nectarine, tangerine, grapefruit,

(2) Acidic fruits orange, pineapple, garambullo, pomegranate, fig, jicama, kiwi, cane, coconut, nanche, tamarind.

(3) Sweet fruits $\quad$ Chicozapote, mamey, plum, jobo, pitahaya, tuna, bananas, grape.

(4) Semi-acid fruits $\quad$ Anona, cherimoya, soursop, peach, mango, apricot, peach, apple, peron, papaya

(5) Melons $\quad$ Watermelon, melon. Concentrates and powders to prepare drinks, Cola and flavor soft drinks and Energy drink.

Source: own elaboration with ENIGH 2018 data. 
considered for this procedure (that is, $K=1$ ) and the measure of distance was taken from the center of one municipality to another.

The application of KNN to the data is correct under the following assumption: "the costs for transportation of the merchandise from one municipality to its nearest neighbor are small in unitary terms; therefore, two municipalities can share the same price for the fruits" because, if that were not the case, the imputation could underestimate the price of the product in places where there is not a reference price.

\section{The AIDS model}

Deaton and Muellbauer (1980) developed a flexible demand system called "Almost Ideal Demand System" (AIDS), which stems from an expenditure function for the PIGLOG type of preferences and the microeconomic theory, to reach the following functional form, feasible to be estimated econometrically.

$$
w_{i}=\alpha_{i}+\sum_{j} \gamma_{i j} \ln P_{j}+\beta_{i} \ln \{X / P\}
$$

Where $w_{i}=$ the participation of the expenditure of group i; $\alpha_{i}=$ the intercept in the equation of group $i$; $\gamma_{i j}=$ the coefficients associated to the interaction of the expenditure from group $i$ and the prices of groups $j_{i} P_{j}=$ the average prices of goods in group $j_{i} \beta_{i}=$ the coefficient associated to the expenditure in group $i$; $X=$ the total expenditure in the set of groups, and $P=$ the index of translog prices defined by:

$$
\ln P=\alpha_{0}+\sum_{k} \alpha_{k} \ln P_{k}+\frac{1}{2} \sum_{j} \cdot \sum_{k} \gamma_{k j} \ln P_{k} \log P_{j}
$$

Where $P_{k}$ and $P_{j}$ are the prices of the goods in the groups $k$ and $j$, respectively.

As Moschini (1998) points out, the AIDS model satisfies automatically the restriction of additivity, homogeneity and symmetry; in the next section, the conditions for each of these restrictions are shown.

Additivity requires:

$$
\sum_{i=1}^{n} \alpha_{i}=1 \quad \sum_{i=1}^{n} \gamma_{i j}=0 \quad \sum_{i=1}^{n} \beta_{i}=0, \quad(k=1,2, \ldots n)
$$

The condition of homogeneity is satisfied if and only if for any $j$ :

$$
\sum_{j} \gamma_{i j}=0
$$

The symmetry is satisfied if:

$$
\gamma_{i j}=\gamma_{j i}
$$

Although in practice it is common to use the Stone price index to linearize the AIDS model and make use of linear estimation methods, such as SUR, it has been shown that this can bring problems of simultaneity bias (Banks et al., 1997; Henningsen). And although this has been attempted to be solved by using other price indexes that are not function of the proportions of expenditure, suggestions have been made for time series. This is why it is suggested to estimate the AIDS model in its nonlinear version; that is, equation (1) was estimated subject to equations (2) to (5).

For this purpose, the algorithm called Iterative Nonlinear Feasible Generalized Least Squares Regression (FGNLS) of the nlsur package of STATA was used, which is relevant for two reasons: 1) it allows estimating systems of non-linear equations; and 2) it relaxes the assumption of homoscedasticity which implies the use of Nonlinear Least Squares, fact that is relevant when used with data at the household level, given that these structures of data usually are not, since it is common for households to be related with one another (Deaton, 2018).

Although all the parameters in (1) and (2) are identified with sufficient variation of independent variables, in many cases the identification of $\alpha_{0}$ (in equation 2) could be problematic. However, this can be surpassed in the practice by assigning a value to $\alpha_{0}$ a priori, given that the parameter can be interpreted as the minimum disbursement of households for the purchase of the groups of goods analyzed (Deaton \& Muellbauer, 1980).

This is why in the empirical applications it has been suggested to equal this parameter to the minimum value of the logarithm of the expenditure observed in the microdata (Banks, Blundell, and Lewbel, 1997). In this study, $\alpha_{0}=0$ is proposed, which leads to the index of translog prices base (2) being the unit, $\mathrm{P}=1$. In addition, as mentioned in Valdes-Zamora (2020), for different values of $\alpha_{0}$, the estimators do not cease to be statistically equal. 
To obtain the elasticities from the AIDS model, it was based on Henningsen. In the case of the expenditure elasticity $\left(e_{i}\right)$, it is obtained when applying the following equation:

$$
e_{i}=1+\left(\frac{1}{w_{i}}\right)\left(\frac{\partial w_{i}}{\partial \ln (x)}\right)=1+\left(\frac{\beta_{i}}{w_{i}}\right)
$$

In turn, the Marshallian elasticities $\left(e_{i j}\right)$ are obtained in the following way:

$$
e_{i j}=-\delta_{i j}+\frac{\gamma_{i j}}{w_{i}}-\frac{\beta_{i}}{w_{i}}\left(\alpha_{j}+\sum_{k=1}^{n} \gamma_{k j} \ln P_{k}\right)
$$

Where $\delta_{i j}$ is Kronecker's delta that is the unit if $i=j$, and zero in the contrary case. It should be noted that the elasticities reported next are national averages and these are obtained as follows: the formulas exposed before are applied to each household and then the mean is obtained by applying their expansion factors.

\section{RESULTS AND DISCUSSION}

Table 2 presents the results from the estimations of the AIDS model, on which the restrictions of additivity, homogeneity and symmetry were imposed. The standard error of each estimator is reported in parenthesis.

For the equation for berries, the estimator that relates them with the expenditure and own price were significant at 95\% of confidence; as well as those related to the price of the sweet fruits, semi-acid fruits, melons and sugary beverages.

In terms of crossed Marshallian elasticities (Table 3), and considering the significance of the crossed parameters, it is found that substitute goods of berries would be sweet fruits and sugary beverages; meanwhile, semiacid fruits and melons would be complementary.

Regarding the own price Marshallian elasticity (main diagonal in Table 3), the six groups analyzed are classified as elastic goods. In particular, for berries, an increase of $1 \%$ in their price, ceteris paribus, is associated to a reduction in the quantity demanded by households of $1.0316 \%$. This result differs from what was found in studies by Martinez and Oropeza (2004) and López et al. (2010); these studies catalogue the fruits that they researched (orange, banana, mango, melon, peach, watermelon, guava, papaya, strawberry, pineapple and grapefruit), and which are part of the groups analyzed, as inelastic goods.

This difference can be because in their studies the authors use prices at the farm level and not prices to the consumer, so they would be estimating the demand elasticities derived or in production, and not the

\begin{tabular}{|c|c|c|c|c|c|c|c|c|}
\hline & $\alpha$ & $\beta$ & $\gamma_{i 1}$ & $\gamma_{i 2}$ & $\gamma_{i 3}$ & $\gamma_{i 4}$ & $\gamma_{i 5}$ & $\gamma_{i 6}$ \\
\hline \multirow{2}{*}{ Berries } & $0.0050^{*}$ & $0.0153^{\star}$ & $-0.0067^{\star}$ & & & & & \\
\hline & $(0.0007)$ & (0.0003) & $(0.0004)$ & & & & & \\
\hline \multirow{2}{*}{ Acidic fruits } & $0.1438^{*}$ & $0.0024^{\star}$ & 0.0004 & $-0.0380^{*}$ & & & & \\
\hline & (0.0019) & $(0.0012)$ & $(0.0004)$ & (0.0018) & & & & \\
\hline \multirow{2}{*}{ Sweet fruits } & $0.1513^{\star}$ & $0.0263^{*}$ & $0.0010 *$ & $-0.0040 *$ & $-0.0285^{\star}$ & & & \\
\hline & $(0.0020)$ & $(0.0012)$ & $(0.0004)$ & (0.0014) & $(0.0019)$ & & & \\
\hline \multirow{2}{*}{ Semi-acidfruits } & $0.0918^{*}$ & $0.1002^{\star}$ & $-0.0041^{\star}$ & $-0.0024^{*}$ & $-0.0220 *$ & $-0.0578^{\star}$ & & \\
\hline & $(0.0020)$ & $(0.0011)$ & $(0.0005)$ & $(0.0014)$ & $(0.0015)$ & $(0.0020)$ & & \\
\hline \multirow{2}{*}{ Melons } & $0.0205^{\star}$ & $0.0314^{\star}$ & $-0.0036^{\star}$ & 0.0083 & $0.0035^{\star}$ & $-0.0139 \star$ & $-0.0245^{\star}$ & \\
\hline & (0.0011) & $(0.0006)$ & $(0.0005)$ & (0.0009) & $(0.0010)$ & $(0.0011)$ & (0.0013) & \\
\hline \multirow{2}{*}{ Sugary drinks } & $0.5876^{\star}$ & $-0.1757^{\star}$ & $0.0130 *$ & $0.0358^{\star}$ & $0.0501^{*}$ & $0.1003^{\star}$ & $0.0303^{*}$ & $0.2296^{\star}$ \\
\hline & $(0.0028)$ & $(0.0018)$ & (0.0003) & (0.0012) & $(0.0013)$ & (0.0013) & $(0.0007)$ & $(0.0022)$ \\
\hline
\end{tabular}
primary or consumption demand,

The asterisk $\left(^{*}\right)$ after the estimator refers to the fact that the estimator value is statistically nonzero at $95 \%$ confidence. Due to symmetry condition, for example, $\gamma_{12}=\gamma_{21}$, the estimator matrix has empty cells. Source: own elaboration. 


\begin{tabular}{|c|c|c|c|c|c|c|c|}
\hline Group & Berries & Acidic fruits & Sweet fruits & $\begin{array}{l}\text { Semi-acid } \\
\text { fruits }\end{array}$ & Melons & Sugary drinks & $\begin{array}{c}\text { Expenditure } \\
\text { Elasticity }\end{array}$ \\
\hline Berries & -1.0316 & -0.0089 & -0.0079 & -0.0297 & -0.0199 & 0.0289 & 1.0691 \\
\hline Acidic fruits & 0.0015 & -1.1806 & -0.0209 & -0.0135 & 0.0382 & 0.1639 & 1.0115 \\
\hline Sweet fruits & 0.0013 & -0.0347 & -1.1412 & -0.1133 & 0.0085 & 0.1676 & 1.1118 \\
\hline Semi-acidfruits & -0.0191 & -0.0545 & -0.1201 & -1.2244 & -0.0575 & 0.1759 & 1.2998 \\
\hline Melons & -0.0184 & 0.0141 & -0.0092 & -0.0812 & -1.1107 & 0.0718 & 1.1336 \\
\hline Sugary drinks & 0.0380 & 0.1409 & 0.1820 & 0.2919 & 0.0879 & -1.3614 & 0.6207 \\
\hline
\end{tabular}

Source: own elaboration with ENIGH 2018 data.

and as is known, the primary demand is more elastic than the derived demand.

It should be mentioned that for the case of sugary beverages, the estimations are similar to what was found by Colchero et al. (2015), who estimated the own price elasticity of 1.16 in absolute terms, while the one found in this study is 1.3614 .

In terms of expenditure elasticities (last column in Table 3), it is found that for all the groups of fruits the expenditure elasticity is higher than one, while sugary beverages are the only ones with elasticities lower than one. That is, based on this, fruits would be luxury goods and sugary beverages a necessary good for the households.

The results obtained for the groups of fruits are similar to those found by Dong et al. (2002), since in their study they classify the aggregate of fruits as luxury goods when reporting an expenditure elasticity of 1.2762 . However, they differ in part from those found by Martinez and Oropeza (2004), since in that study they only classified the melons and oranges as luxury goods, while the rest of the fruits analyzed as necessary goods. López et al. (2010) also reported in their study that not all citruses were luxury goods.

One of the virtues of working with microdata vs time series is the incorporation of demographic variables. In this sense, although they were not incorporated in the estimation of the AIDS model, when obtaining the elasticities per household it was possible to recover the average elasticities at the state level (Figure 1).

Figure 1 shows maps of the national territory and on them the own expenditure and price elasticities at the level of state household for berries, obtained from the AIDS model.

The interpretation of expenditure elasticities (left side) is evident, darker tonalities reflect higher expenditure elasticities; in this sense, states in the center of the country like Puebla and Querétaro exhibit the highest expenditure elasticities (1.079 and 1.076, respectively), while Tabasco and southeastern states (Yucatán, Quintana Roo) present the lowest expenditure elasticities (1.0465, 1.0504 and 1.0514), respectively.
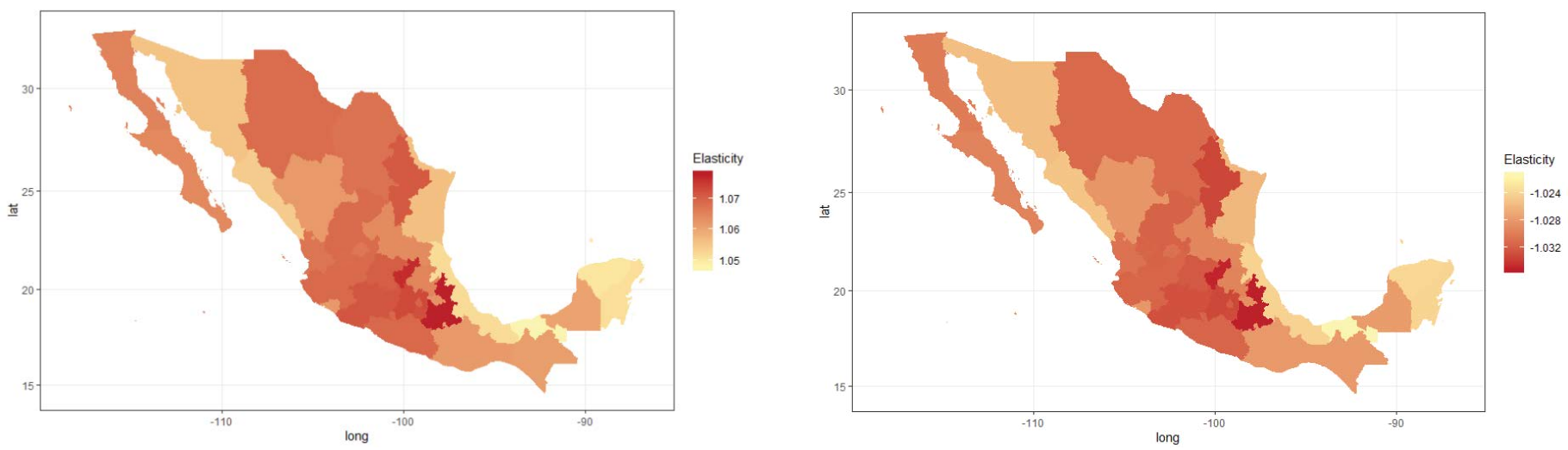

Figure 1. Statewide average expenditure (left side) and Marshallian own price elasticities (right side), AIDS model. Source: own elaboration with ENIGH 2018 data 
In terms of the own price elasticities of berries (Figure $1 \mathrm{~B})$, darker tonalities are related to higher elasticities in absolute terms. Thus, and contrary to the case of expenditure elasticity, states like Veracruz and south and southeastern states are less elastic to changes in the price of berries, while in the center of the country (Puebla and Querétaro) there are higher elasticities.

This accounts for the heterogeneity that demand for berries has in the long term. It would be expected to observe that, facing a generalized increase of expenditure, the consumption would increase much more in the center of the country versus the south-southeast. Meanwhile, if the price increases in the same way, the trend would be different; that is, a greater contraction of the consumption in the center of the country versus the south-southeast would be expected.

\section{CONCLUSIONS}

According to the own price elasticity of berries and sugary beverages analyzed, it is found that all of them are elastic goods $\left(E_{p}>1\right)$; in terms of crossed Marshalian elasticities, it was found that according to the model, the substitute goods for berries would be sugary beverages $\left(E_{i j}=0.0289\right)$; meanwhile, the sweet fruits, semi-acid fruits and melons would be complementary $\left(E_{i j}=-0.079\right.$, $E_{i j}=-0.0297, E_{i j}=0.0199$, respectively).

When analyzing the expenditure elasticities, berries, same as the rest of the fruit groups, are luxury goods with elasticities higher than one. For berries, the average elasticity is 1.0691 . The opposite is the case of sugary beverages, with elasticity of 0.6207 , which classifies it as a necessary good. Finally, in light of the findings mentioned of national average, there is also the fact that there are state differences in the response to changes in prices and income compared to the demand for berries, so that in the long term, it would be expected to observe that when facing a generalized increase of income in the households, the consumption will increase much more in the center of the country versus the south-southeast, contrary case to a generalized increase of their price.

\section{REFERENCES}

Banks, J., Blundell, R., \& Lewbel, A. (1997). Quadratic Engel Curves and Consumer Demand. The Review of Economics and Statistics, 79(4), 527-539

Colchero, M. A., Salgado, J. C., Unar-Munguía, M., Hernández-Ávila, M., \& Rivera-Dommarco, J. A. (2015). Price elasticity of the demand for sugar sweetened beverages and soft drinks in Mexico. Economics \& Human Biology, 19, 129-137. https://doi.org/ https://doi.org/10.1016/j.ehb.2015.08.007

Deaton, A. (2018). The analysis of household surveys (1st ed.) Washington, D.C.: Worl Bank

Deaton, A., \& Muellbauer, J. (1980). An Almost Ideal Demand System (1954).

Dong, D., Gould, B. W., \& Kaiser, H. M. (2002). The Structure of Food Demand in Mexico: An Application of the Amemiya-Tobin Approach to the Estimation of a Censored System. 2002 Annual Meeting American Agricultural Economics Association Long Beach, CA.

FIRA. (2016). Panorama Agroalimentario | Berries 2016. Fideicomisos Instituidos en Relacion con la agricultura (Vol. 2016)

Henningsen, A. (n.d.). Demand Analysis with the "Almost Ideal Demand System" in R: Package micEconAids

López, M. A., Valdivia, R., Hernández, J., \& Romo, J. L. (2010) Elasticidades y flexibilidades de los productos citrícolas en México Elasticities and flexibilities of citrus products in Mexico Revista Mexicana de Economia Agricola y de Los Recursos Naturales, III(2), 97-112.

Martinez, M. Á., \& Oropeza, J. A. (2004). Un sistema de Demanda Casi Ideal (AIDS) aplicado a once frutas en México (1960-1998) Revista Fitotecnia Mexicana, 27(4), 367-375

Miller, K., Feucht, W., \& Schmid, M. (2019). Bioactive Compounds of Strawberry and Blueberry and Their Potential Health Effects Based on Human Intervention Studies: A Brief Overview. Nutrients, 11(7), 1510. https://doi.org/10.3390/nu11071510

Moschini, G. (1998). The semiflexible almost idela demand system European Economic Review, 42(2), 349-364

Rivera, J., \& Blanco, J. (2018). Berries: Rutas Tecnológicas 2014-2018. Jalisco, México

Solverson, P. M., Rumpler, W. V. Leger, J. L., Redan, B. W., Ferruzzi, M. G., Baer, D. J., ... Novotny, J. A. (2018). Blackberry Feeding Increases Fat Oxidation and Improves Insulin Sensitivity in Overweight and Obese Males. Nutrients, 10(8), 1048. https:// doi.org/10.3390/nu10081048

\section{1

